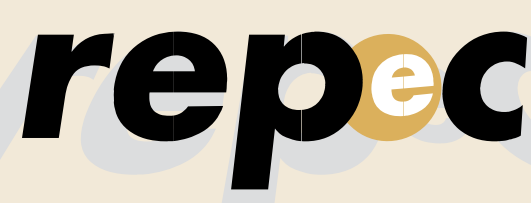

REPeC, Brasília, v. 11, n. 4, índice por títulos, p. 494-470, out./dez. 2017

Disponivel online em www.repec.org.br
Revista de Educação e Pesquisa em Contabilidade Journal of Education and Research in Accounting

Periódico Trimestral, digital e gratuito publicado pela Academia Brasileira de Ciências Contábeis

ISSN 1981-8610

\title{
ÍNDICE POR TÍTULOS - 2017
}

A Constituição do Campo Científico e a Baixa Diversidade da Pesquisa Contábil Brasileira

Paulo Frederico Homero Junior

Repec, Brasília, v. 11, n. 3, art. 4, p. 314-328, jul./set. 2017.

A Síndrome de Burnout em Estudantes de Ciências Contábeis de IES Privadas: Pesquisa na Cidade de São Paulo Ivam Ricardo Peleias, Erotides Rocha Guimarães, Betty Lilian Chan, Mary Sandra Carlotto REPeC, Brasília, v. 11, n. 1, art. 2, p. 30-51, jan./mar. 2017.

A Visão da Academia e do Mercado de Trabalho sobre o Ensino da Auditoria Jhonatan Hoff, Luiz Alberton, Rita de Cássia Correa Pepinelli Camargo REPeC, Brasília, v. 11, n. 1, art. 3, p. 52-68, jan./mar. 2017.

As Estratégias de Aprendizagem Autorregulada (SRL) no Ensino EAD de Contabilidade Thiago Bruno de Jesus Silva, Luis Antonio Lay, Nelson Hein, Vania Tanira Biavatti, Vinícius Costa da Silva Zonatto REPeC, Brasília, v. 11, n. 1, art. 5, p. 90-109, jan./mar. 2017.

Agressividade tributária: um survey da literatura Antonio Lopo Martinez REPeC, Brasília, v. 11, Edição Especial, art. 6, p. 111-129, 2017.

Avaliação das Competências Docentes: Análise no Curso de Ciências Contábeis da UTFPR Patrícia Zanella, Ricardo Adriano Antonelli, Sandro César Bortoluzzi REPeC, Brasília, v. 11, n. 2, art. 2, p. 150-167, abr./jun. 2017.

Big Data: Reflexões epistemológicas e impactos nos estudos de finanças e mercado de capitais Talieh Shaikhzadeh Vahdat Ferreira, Francisco José da Costa REPeC, Brasília, v.11, n. 4, art. 2, p. 396-407, out./dez. 2017.

Características e Perspectivas Internacionais dos Diversos Grupos de Interesses em Relação à IFRS SME's Juçara Haveroth, Evandro De Nez, Ângela Bilk, Roberto Carlos Klann REPeC, Brasília, v. 11, n. 4, art. 4, p. 430-450, out./dez. 2017.

Caso de Ensino: A Alocação de Custos Conjuntos em Processos com Múltiplos Pontos de Separação na Refinaria Fluminense S.A.

Raphael da Fonseca, Moacir Sancovschi REPeC, Brasília, v. 11, n. 2, art. 6, p. 231-253, abr./jun. 2017.

Caso de Ensino: Liquidez ou Solvência, de Quem é a Culpa? A Análise Econômico-Financeira de Uma Instituição Financeira

José Américo Pereira Antunes, Renata Sol Leite Ferreira da Costa, José Elias Feres de Almeida REPeC, Brasília, v. 11, n. 3, art. 6, p. 347-361, jul./set. 2017.

Comportamento e Particularidades da Produção Academia do Tema “Contabilidade Gerencial” Divulgada na Base de Dados do ISI WEB of Science Core Collection de 1985 a 2014

Henrique César Melo Ribeiro, Vanessa Carvalho Miranda Tavares REPeC, Brasília, v. 11, n. 1, art. 1, p. 5-29, jan./mar. 2017.

Compreensão dos Graduandos dos Cursos de Ciências Contábeis quanto aos Conceitos Relevantes Ensinados na Disciplina de Teoria da Contabilidade em IES da Grande Florianópolis

Fabiana Frigo Souza, Ernesto Fernando Rodrigues Vicente REPeC, Brasília, v. 11, n. 1, art. 6, p. 110-126, jan./mar. 2017.

Contabilidade das operações de leasing: Análise de possíveis ocorrências de lobbying no processo de emissão da IFRS 16

Fábio Henrique Ferreira de Albuquerque, Manuela Maria Marcelino, Nuno Miguel Barroso Rodrigues, António José Rodrigues de Almeida Cariano REPeC, Brasília, v. 11, n. 4, art. 6, p. 467-484, out./dez. 2017.

Determinantes da Qualidade da Informação Contábil em Grandes Companhias Abertas Listadas na BM\&FBOVESPA

Geovanne Dias de Moura, Mayara Zanchi, Sady Mazzioni, Francisca Francivânia Rodrigues Ribeiro Macêdo REPeC, Brasília, v. 11, n. 3, art. 5, p. 329-346, jul./set. 2017. 
Determinantes das Republicações no Mercado Brasileiro: Uma Análise a Partir dos Incentivos ao Gerenciamento de Resultados

Vagner Antônio Marques, Hudson Fernandes Amaral, Antônio Artur de Souza, Kleyverson Leonardo dos Santos, Pedro Henrique Rodrigues Belo

REPeC, Brasília, v.11, n. 2, art. 4, p. 191-213, abr./jun. 2017.

Diferenças de aprendizagem autodeterminada em estudantes de pós-graduação: Uma análise relacionando grupo de idade e gênero ao uso de estratégias

Raimundo Nonato Lima Filho, Silvia Pereira de Castro Casa Nova

REPeC, Brasília, v. 11, n. 4, art. 1, p. 370-395, out./dez. 2017.

ENADE e Proposta Curricular do CFC: Um Estudo em Cursos Brasileiros de Ciências Contábeis

Vanessa Ramos da Silva, Gilberto José Miranda, Janser Moura Pereira

REPeC, Brasília, v. 11, n. 3., art. 1, p. 261-275, jul./set. 2017.

Estrutura de capital e Governança Corporativa nas empresas listadas na BM\&FBovespa

Bruno Goes Pinheiro, Alessandra Carvalho de Vasconcelos, Márcia Martins Mendes De Luca,m Vicente Lima

Crisóstomo

REPeC, Brasília, v. 11, n. 4, art. 5, p. 451-466, out./dez. 2017.

Estudos Internacionais Sobre Valor Justo (2000-2016): Temáticas, Métodos e Sugestôes de Pesquisas Futuras Eduardo Bona, Lucas Vieira Lôbo de Araújo, Mariana Guerra, Fernando Dal-Ri Murcia Repec, Brasília, v. 11, n. 3, art. 2, p. 276-295, jul./set. 2017.

Habilidades Relevantes para a Perícia Contábil Criminal: A Percepção dos Peritos e Delegados da Polícia Federal Carlos Roberto dos Santos Filho, Flávio Alves Carlos, Fábio Moraes da Costa REPeC, Brasília, v. 11, n. 1, art. 4, p. 69-89, jan./mar. 2017.

Mapa conceitual da fraude: configuração teórica e empírica dos estudos internacionais e oportunidades de pesquisas futuras

Lucas Martins Dias Maragno, José Alonso Borba

REPeC, Brasília, v. 11, Edição Especial, art. 3, p. 45-72, 2017.

O Goodwill gerado pelo Passivo

Eliseu Martins, Ariovaldo dos Santos

REPeC, Brasília, v. 11, Edição Especial, art. 1, p. 11-23, 2017.

O que me Ensina a Ensinar? Um Estudo Sobre Fatores Explicativos das Práticas pedagógicas no Ensino de

Contabilidade

Uilcleides Braga da Silva, Adriano Leal Bruni

REPeC, Brasília, v.11, n.2, art. 5, p. 214-230, abr./jun. 2017.

O que se tem pesquisado sobre Sustentabilidade Empresarial e sua Evidenciação?

Valcemiro Nossa, Victor Rangel dos Santos Rodrigues, Silvania Neris Nossa

REPeC, Brasília, v. 11, Edição Especial, art. 5, p. 91-109, 2017.

Presença do Gênero Feminino entre Discentes dos programas de Pós-Graduação de Ciências Contábeis no Brasil Daniele Cristina Bernd, Marcielle Anzilago, Ilse Maria Beuren REPeC, Brasília, v. 11, n.4, art. 3, p. 408-429, out./dez. 2017.

Relação entre percepção de justiça organizacional e satisfação no trabalho Ilse Maria Beuren, Vanderlei dos Santos, Leandro Marques, Michel Resendes REPeC, Brasília, v. 11, Edição Especial, art. 4, p. 73-90, 2017.

Sustentabilidade Empresarial e Governança Corporativa: Uma Análise da relação do ISE da BM\&FBOVESPA com a Compensação dos Gestores de Empresas Brasileiras

Thayse Machado Guimarães, Fernanda Maciel Peixoto, Luciana Carvalho

REPeC, Brasília, v. 11, n. 2, art. 1, p. 134-149, abr./jun. 2017.

Taxonomia do Dark Triad: Revelações da Rede Científica no Meio Organizacional

Márcia Figueredo D'Souza, Daniel N. Jones

REPeC, Brasília, v. 11, n. 3, art. 3, p. 296-313, jul./set. 2017.

Teoria em Cena: A Produção de Vídeo Como Instrumento no Ensino da Contabilidade

Ana Maria Beatriz Sardela, Patrícia de Souza Costa, Gilvania de Sousa Gomes REPeC, Brasília, v. 11, n. 3, art. 1, p. 168-190, abr./jun. 2017.

Trinta anos de pesquisa em remuneração executiva e retorno para 0 acionista Juliano Augusto Orsi de Araujo, Maísa de Souza Ribeiro REPeC, Brasília, Edição Especial, art. 2, p. 25-44, 2017. 